\title{
Klazomania: A Rare Case of Compulsive Screaming, Complicating Major Depression, Effectively Treated with Electroconvulsive Therapy (ECT)
}

Prashanth Pillai ${ }^{*}$ Nithin Krishna and William Regenold

Department of Psychiatry, University of Maryland, USA

"Corresponding author: Prashanth Pillai, Department of Psychiatry, School of Medicine, University of Maryland, USA, Tel: 202-412-2984; E-mail: drpillai.mail@gmail.com

Received date: October 24, 2016; Accepted date: February 07, 2017; Published date: February 10, 2017

Copyright: ( 2017 Pillai P, et al. This is an open-access article distributed under the terms of the Creative Commons Attribution License, which permits unrestricted use, distribution, and reproduction in any medium, provided the original author and source are credited.

\begin{abstract}
We describe a rare case of a 57-year-old women diagnosed with Klazomania (compulsive shouting), rarely reported in literature, complicated by Major Depressive Disorder (MDD), refractory to medical management and treated successfully using electroconvulsive therapy (ECT). This is a unique presentation in which compulsions occurring in the context of MDD involved shouting rather than more typical compulsions such as hand washing or counting. Potential neurological disorders were ruled out through an extensive diagnostic workup prior to a course of electroconvulsive therapy (ECT). Her episodic compulsive shouting abated and eventually remitted after a 12session course of ECT.
\end{abstract}

Keywords: Klazomania; Compulsive screaming; ECT; Complication of major depression; Adult psychiatry; Elderly depression; Elderly screaming; Aging psychiatry

\section{Case Report}

Ms. X, a 57-year-old Ethiopian woman was admitted to the psychiatric service with a 2 -year history of increasingly frequent episodic paroxysmal compulsive shouting (from once every month to a quotidian occurrence), complicated by treatment resistant Major Depressive Disorder (MDD). The shouting episodes were characterized by loud screaming and screeching sounds, occasionally in speech that was perseverative and stereotypic with small sentences, and concurrently accompanied by crying. During these episodes, she was completely oriented; aware she was screaming and able to recollect her thoughts. Afterwards, she reported feeling anxious and irritated because of her inability to control her vocalizations. The episodes occurred daily, 3-7 per hour every hour she was awake, variable in duration, and were emotionally consonant with her mood state (precipitated by intrusive thoughts of a recently deceased fiance). They occurred in a variety of settings (work, home, social) that affected her quality of life and interfered with her work performance. She was admitted twice on previous occasions for the same complaint.

Her psychiatric history was significant for MDD that was likely triggered by several major life stressors beginning with the death of her fiancé 2-years prior. During this time she developed severe depression characterized by a low mood, decreased energy, poor concentration, sleep disturbances, lack of appetite, anhedonia, and feelings of worthlessness and hopelessness. As mentioned earlier, it was also during this period that her shouting episodes gradually increased in frequency to a quotidian occurrence. She endorsed no history of hallucinations or head trauma. Ms. X's past medical history was significant for Type 2 Diabetes Mellitus, Hypertension, Chronic Back and Neck Pain, Anxiety, and Mood disturbances. Family history was unremarkable for psychiatric or neurological disorders. Her home medications included Citalopram $40 \mathrm{mg}$ QD, Risperidone $0.5 \mathrm{mg}$ BID, Clonazepam $0.25 \mathrm{mg}$ BID, Tramadol $25 \mathrm{mg}$ as needed (for back pain),
Hydroxyzine $25 \mathrm{mg}$ QD (at night), and Metformin $500 \mathrm{mg}$ QD. She denied use of alcohol or illicit substances.

Laboratory evaluations, Lumbar Puncture (LP) revealed a slightly elevated protein level of $60 \mathrm{~mm} / \mathrm{dL}$ (otherwise LP results were within normal limits), a Electroencephalogram (EEG) with and without vocalizations was negative, and a Head-CT revealed periventricular white matter hypodensities with global atrophy. Magnetic Resonance Imaging (MRI) was remarkable for numerous deep white matter foci of signal hyperintensity, predominantly frontal and greater than typically seen in patients of similar age without Hypertension. On Physical Exam, Ms. X was alert and oriented to time, place, and person, with normal Vitals. A skin exam revealed multiple hyperpigmented café-aulait spots on the dorsum of her torso. Her Mental Status Exam (MMSE) score was 29/30 with speech that was logical and goal-directed. A neurologic exam also revealed a stooped posture, abnormal gait with small steps, a mild bilateral intentional tremor and a give away rigidity in upper extremities. A diagnosis of Klazomania (CS) complicated by MDD was given.

Pharmacotherapy trials prior to admissions with Fluoxetine, Paroxetine, Clomipramine, Citalopram, and Risperidone, at therapeutic doses and adequate durations, along with behavioral approaches were tried and did little to abate her symptoms. On the current admission, Citalopram was decreased to $20 \mathrm{mg}$ daily due to concern about interactions with Tramadol. Risperidone was discontinued on concerns of extrapyramidal symptoms (EPS) that were affecting her gait, posture, and muscle rigidity. Clonazepam was discontinued in favor of Lorazepam $0.5 \mathrm{mg}$ (BID for anxiety and agitation) and was maintained until her discharge. Subsequent ECT (12 sessions, 3 times per week) added to her treatment regiment proved beneficial. Her vocalizations improved around the $4^{\text {th }}$ session and eventually resolved. Over the course of the 12 ECT sessions Ms. X's Citalopram was titrated to a final dose of $60 \mathrm{mg}$ daily, and her depression improved significantly by the 12th session, indicated by the improvement in her Hamilton Depression Rating Scale (HAM-D-21, scores before were in the 40's and at completion between 2-5 points). Her MMSE scores remained stable through out the 12 ECT sessions. 


\section{Discussion}

Benedek coined the term 'klazomania' in 1925 to describe compulsive shouting associated with motor tics in the context of postencephalitic Parkinsonism [1]. This condition has also been noted in persons with various other neurological insults, including carbon monoxide poisoning [1,2]. And compulsive or continuous shouting has been noted, as an infrequent but highly disruptive symptom, in adults with intellectual disabilities or advanced dementia. However, there is no consensus on whether screaming is a meaningful attempt at communication or merely a type of agitation [3]. Electroconvulsive therapy (ECT) has been demonstrated to be effective for screaming behavior in patients with mental retardation or dementia, particularly in the presence of depression [4,5]. To our knowledge compulsive screaming has not been observed as a symptom of an Affective Disorder in the absence of an intellectual disability or a neurodegenerative disorder.

Ms. X had no remarkable symptom or history that required further work-up for ruling out unlikely causes for CS (poisoning, intellectual disability, neurodegenerative, infections). The compulsive screaming observed in this patient shares similar features observed in tic-like disorders [6], Klazomania [1,2], and typical depression with comorbid obsessive-compulsive traits [7]. Our patient's psychopathology was complicated by severe depression and an inability to control her episodes of paroxysmal shouting. Her screaming served no purpose and the content of the vocalizations were repetitive and non-rhythmic. A diagnosis of adult onset vocal tics is unlikely as it is rare and commonly associated with 'triggering' events such as physical trauma, viral infection, or exposure to drugs [6]. Lastly, psychological stressors, such as death of a loved one, have not previously been associated with the onset of new vocal tics.

Although there has been limited scientific literature on MDD with comorbid obsessive-compulsive traits, studies do examine both Typical and Atypical comorbid Depression in the presence of Obsessive Compulsive Disorder (OCD), which has a prevalence of about $10 \%$ [8], implying the possibility of a shared etiopathology [7]. In our case, the patient's obsessive thoughts of her deceased fiancée precipitated compulsive shouting and the nature of her vocalizations (perseverative and repetitive) prompted us to explore this shared etiopathology. There are also some similarities to Fronto-Temporal dementia (FTD) as see in this case related to the frontal-temporal atrophy, a possibility that the shouting is an impulsive behavior, apathy, and motor symptoms. But this is less likely because our patient lacks the extensive symptomology of FTD, no sig family history of dementia, her ruminations were consonant with her mood, and more over that her symptoms improved with changes in her therapeutic regimen (ECT +titrated Citalopram). Seizure disorder is also an unlikely diagnosis because of the negative EEG; furthermore no history of head trauma was reported.

Given the patient's country of origin, we considered the possibility of a culture-specific explanation for her presentation. Episodes of unusual vocalizations and movements have been described as part of illness behavior among Ethiopian immigrants, attributed to the ghostly possession of the human body by 'Zar', a spirit form [9]. Zar possession, as described in Ethiopian immigrants to the state of Israel, may function as a means of rallying social support. However, Ms. X did not attribute her symptoms to spirits, or make reference to the necessity of particular ceremonies. Both the patient and her family felt her screaming and crying was unusual by their cultural standards.

\section{Conclusion}

This case represents a unique presentation where compulsive screaming developed concurrently with Major Depressive Disorder, in a female, without evidence of a neurological lesion or dementia, and without a history of OCD or Tourette's syndrome. We found no clear etiology to this case of Klazomania. Neurophysiologic testing was not completed and would have shed more light on the diagnosis. However, as in other cases of compulsive shouting associated with depressive symptoms, Electroconvulsive Therapy (ECT) proved to be an effective treatment modality to successfully abate symptoms in our patient [10]. Neurophysiologic testing was not completed and would have shed more light on the diagnosis.

\section{Acknowledgement}

None

\section{Conflicts}

None

\section{References}

1. Bates GDL, Lampert I, Prendergast M, Van Woerkom AE (1996) Klazomania: The screaming tic. Neurocase 2: 31-34.

2. Walsh PJ (1962) Compulsive shouting and Gilles de la Tourette's disease. Br J Clin Pract 16: 651-655.

3. Bourbonnais A, Ducharme F (2008) Screaming in elderly persons with dementia: A critical review of the literature. Dementia 7: 205-225.

4. Snowdon J, Meehan T, Halpin R (1994) Continuous screaming controlled by electroconvulsive therapy: A case study. Int J Geriat Psychiatry 9: 929-932.

5. Carlyle W, Killick L, Ancill R (1991) ECT: an effective treatment in the screaming demented patient. J Am Geriatr Soc 39: 637

6. Eapen V, Lees AJ, Lakke JP, Trimble MR, Robertson MM (2002) Adultonset tic disorders. Mov Disord 17: 735-740.

7. Overbeek T, Schruers K, Vermetten E, Griez E (2002) Comorbidity of obsessive-compulsive disorder and depression: prevalence, symptom severity and treatment effect: J Clin Psychiatry 63: 1106-1112.

8. Singh T, Williams K (2006) Atypical Depression: Psychiatry (Edgmont) 3: 33-39.

9. Witztum E, Grisaru N, Budowski D (1996) The 'Zar' possession syndrome among Ethiopian immigrants to Israel: Cultural and clinical aspects. Br J Med Psychol 69: 207-225.

10. Rapoport M, Feder V, Sandor P (1998) Response of major depression and Tourette's syndrome to ECT: a case report. Psychosom Med 60: 528-529. 